\title{
Amistad y adversidad: la escuela como un espacio de encuentro y acompañamiento en un contexto de violencia crónica en el norte de Monterrey*
}

\author{
Friendship and adversity: the school as a meeting and \\ companionship space in a context of chronic violence in the \\ north side of Monterrey, Mexico
}

DOI: https://doi.org/10.32870/dse.v0i24.1043

\section{Gabriela Sánchez López**}

\section{Resumen}

En México la violencia es un problema crónico que se ha intensificado en los últimos años. En 2019 murieron de forma violenta aproximadamente 36,476 personas, lo que se expresa en una tasa de 29 homicidios por cada 100 mil habitantes (INEGl, 2020). El presente artículo elabora una discusión sobre la violencia crónica desde las tramas narrativas y las formas de acompañamiento que niñas y niños tejen en el entorno escolar. Utilizando una metodología participativa de corte etnográfico que promueve la narración de historias sobre la vida cotidiana, se documentaron más de 82 relatos en dos escuelas de un barrio al norte de Monterrey en donde la muerte violenta y las prácticas de despojo se han sostenido desde hace más de una década. Se realizaron también entrevistas con funcionarias para la protección de los derechos de niñas, niños y adolescentes que atendían a ese sector, algunas madres, abuelas o tías, y diferentes actores sociales y vecinos del espacio escolar. El estudio revela el potencial de la escuela como una esfera afectiva importante y brinda elementos para la comprensión de las relaciones horizontales entre niñas y niños, que buscan dar sentido a las situaciones de violencia que viven, produciendo espacios y relaciones de escucha, acompañamiento y contención.

Palabras clave: escuela - infancias - violencia crónica - narrativas - etnografía.

\section{Abstract}

In Mexico, violence is a chronic problem that has intensified in recent years. In 2019, approximately 36,476 people died violently, which is expressed in a rate of 29 homicides per 100,000 inhabitants (INEGI, 2020). This article discusses chronic violence through the narratives and the forms of accompaniment of girls

* Agradecimiento. Agradezco el apoyo del Consejo Nacional de Ciencias y Tecnología (Conacyt) por el apoyo como becaria posdoctoral en el marco del Proyecto CB-2016/285477 titulado "Infancias amputadas, adolescencias en riesgo. Niñez y violencia crónica en el noreste de México". Mi gratitud se extiende a la orientación y acompañamiento de la Dra. Séverine Durin, coordinadora del proyecto y el apoyo de la Defensoría Municipal para la Protección de NNA de Monterrey, por todas las facilidades para realizar este trabajo.

** Doctora en Antropología Social. Líneas de investigación: salud psicosocial; políticas de atención psicosocial y humanitaria; infancias y violencias. Profesora-Investigadora, Departamento de Psicología Educación y Salud, Instituto Tecnológico y de Estudios Superiores de Occidente (ITESO), Guadalajara. México. gabriela.sanchez@iteso.mx 
and boys in the school environment. Using a participatory ethnographic methodology that promoted the narration of stories about daily life, more than 82 stories were documented in two schools in a neighborhood in the north of Monterrey, Mexico where violent death and dispossession practices have been taking place for over a decade. We also conducted interviews with officials for the protection of the rights of girls, boys and adolescents who attend this sector, as well as with students' mothers, grandmothers, or aunts, and different social actors and neighbors of the school. The study reveals the potential of the school as an important emotional environment and provides elements to understand the horizontal relationship between girls and boys trying make sense of the violent situations they experience, creating spaces and relationships of mutual listening, companionship, and contention.

Keywords: school - childhood - chronic violence - narratives - ethnography.

\section{Antecedentes}

Después de la familia, la escuela constituye el entorno social más próximo para la mayoría de las niñas y los niños, y el espacio en que tienen lugar los primeros encuentros con aquellos que habitan fuera del ámbito doméstico y en la inmediata vecindad. La comunidad escolar y el territorio donde viven son también los espacios donde reciben los servicios públicos y, por lo tanto, donde se da la relación de las instituciones del Estado con la niñez. El tiempo que pasan en la escuela estructura de forma importante el día a día y los arreglos familiares de sus hogares para distribuir actividades laborales y de cuidados. Más allá de la educación formal, entre los muros, pasillos y patios de las escuelas circulan conocimientos, saberes y prácticas que son centrales para la construcción de las subjetividades infantiles.

Ahora bien, es innegable que las escuelas están insertas en contextos sociales violentos y que la amplitud del fenómeno de la violencia sobrepasa los límites escolares, integrando las tensiones propias de los entornos sociales. En efecto, los datos estadísticos sobre violencia escolar revelan una realidad preocupante. ${ }^{1}$ Sin embargo, estos representan la expresión de violencias estructurales e históricas, y no necesariamente la caracterización de la escuela como un espacio exclusivamente peligroso para las infancias. Además de la violencia en la escuela, existen otras lógicas de expresión de las violencias, como la violencia contra la escuela y de la escuela (Charlot, 2002). Las fronteras entre estas lógicas son porosas y coexisten interrelacionadas. En el caso de la violencia contra la escuela, es común el saqueo y la destrucción de los planteles. Desde

1 La Consulta Infantil y Juvenil de 2018 revela que la escuela, después del hogar, es el espacio en que los menores manifiestan enfrentar más violencias, malos tratos y discriminación (INE, 2019). En el mismo tenor, la Encuesta Nacional de Salud y Nutrición muestra que la escuela es el segundo lugar en que más frecuentemente la niñez ha sufrido violencias, siendo esta situación más grave entre las niñas (ENSANUT, 2020). De acuerdo con una encuesta del Instituto Nacional de Evaluación de la Educación (INEE, 2018), seis de cada diez alumnos de educación básica observaron insultos y golpes por parte de sus compañeros, datos secundados por la Encuesta Nacional sobre Discriminación (ENADIS, 2017), la cual da cuenta de que un tercio de los niños y un cuarto de las niñas reportaron haber vivido violencia física y amenazas en su escuela. 
la lógica de la violencia de la escuela, el dispositivo escolar reproduce violencias cotidianas de poder y subordinación adultocéntrica.

A pesar de que la escuela sea una arena de tensiones, productora y reproductora de formas de violencia y discriminación, es también, como se propone en este artículo, un lugar ambivalente donde se gestan relaciones de amistad y acompañamiento que ayudan a enfrentar las violencias cotidianas. Por ese motivo, la escuela es una esfera afectiva importante para la niñez donde se tejen vínculos de confianza y cooperación, pero también, conflictos y enemistades que, en conjunto, ayudan a fraguar nuevas alianzas y estrategias para reponerse de fracasos cotidianos. Es en la escuela donde niñas y niños se construyen como tales, en sus propios términos, a pesar de los mandatos de familiares y docentes, desarrollando prácticas de resistencia ante las formas institucionalizadas de normalizar las infancias (Tassinari, Almeida, Rebolledo, 2014).

Más que un estudio sobre la violencia escolar, la violencia en la escuela o por la escuela, este artículo ofrece un análisis de las narrativas y experiencias que niñas y niños comparten desde la escuela, en un entorno donde la muerte violenta, el abuso y las prácticas de despojo se han sostenido desde hace más de una década.

El objetivo es identificar, describir y analizar la escuela como un espacio de encuentro donde las infancias construyen relaciones afectivas y de acompañamiento en contextos de violencia crónica. En particular, se rescatan pasajes etnográficos que tienen el propósito de visibilizar quién escucha a las infancias que viven bajo estas condiciones, qué comparten y con quiénes hablan estas niñas y niños. Con ese propósito, se organiza una discusión sobre las implicaciones de la violencia crónica en las infancias, a través del abordaje antropológico de las narrativas de niñas y niños como forma de interpretación de la experiencia individual y colectiva.

\section{Crecer con la violencia: los embates de una generación}

A más de diez años del inicio de la crisis de seguridad nacional y de derechos humanos en el país, las consecuencias de las políticas desplegadas por el gobierno de Felipe Calderón (20062012) para militarizar la seguridad pública están lejos de ser secundarias, desdoblándose en un catálogo de violencias que se reproducen, persisten y recrudecen, anidando en la vida cotidiana de niñas y niños mexicanos que han crecido durante este periodo. Una tercera parte de la población de México son niñas, niños y adolescentes, de los cuales, dos de cada diez nacieron y crecieron en los últimos doce años (ENADIS, 2018), es decir, durante el periodo de repunte e intensificación histórica de la violencia. Pero no todos ellos viven o vivieron sus infancias en contextos dominados por la violencia, en buena medida porque la operatividad de la estrategia de seguridad pública del Estado fue, y sigue siendo, regionalizada.

Como resultado, la violencia tiende a localizarse y recrudecerse en áreas específicas y geográficamente cercanas (Reyes, Hernández, Moslares, 2015). En estos lugares la violencia ha pe- 
netrado en todos los espacios que históricamente han sido fundamentales para la socialización de las infancias y la construcción de sus capacidades psicosociales, como son el hogar, la escuela y el espacio público. Por ese motivo, el concepto de violencia crónica es particularmente operativo en el desarrollo de este análisis, ya que busca visibilizar los efectos de la violencia en sus múltiples dimensiones y expresiones (Pearce, 2019). Esto incluye las formas de violencia armada no convencional, es decir, aquellas que se reproducen en economías ilícitas que utilizan como vehículo la intimidación y la violencia, y se perpetúan por la corrupción e impunidad. Estas violencias estructuran la vida cotidiana pues se han "incrustado en las comunidades y la vida familiar" (Adams, 2014: 1, traducción propia). En estos contextos, el registro continuo de muertes violentas y otros actos frecuentes de violencia que no terminan en muerte, expresan la cronicidad de la violencia (Pearce, 2019). Este es el caso particular del contexto estudiado, donde la violencia sexual y de género, los homicidios y desapariciones forzadas se han sostenido con algunas variaciones desde 2008 a la fecha (ONODC, 2018).

Independientemente de la regionalización de la violencia en el país, muchas niñas y niños están creciendo en contextos regidos por violencias cotidianas que se configuran bajo un sentido de normalidad, y perduran en un régimen de amplia impunidad (Robledo, 2019). Esta generación comprende, de manera particular, a todos aquellos nacidos a partir de 2009. Coincido con Guita Debert (1998: 60) cuando señala que "la generación no se refiere a las personas que comparten la edad, sino a las que vivenciaron determinados eventos que definen trayectorias pasadas y futuras". En ese sentido, este estudio se enfoca en una generación específica, aquella que nació y ha crecido en entornos donde la violencia se perpetúa y se recrudece.

Las experiencias y el desarrollo de esta generación han estado marcados por la reconfiguración de sus espacios de socialización con motivo de la violencia. Muchos de ellos han debido huir de los lugares donde vivían por esta razón. Han vivido el reacomodo de sus familias tras el asesinato o la desaparición forzada de uno o ambos progenitores, o bien de alguno de sus familiares. Han sido testigos de actos violentos en la proximidad de las calles y barrios en los que viven, $y$ en las escuelas donde estudian. Otros muchos han sido objeto de la violencia policiaca o criminalizados por los delitos imputados a sus familias y comunidades. A las víctimas de este estado de guerra se suman los hijos de policías, militares y otros actores armados, incluyendo los de los empleados de seguridad privada. No son pocos los que han sido abusados sexualmente y viven en hogares en donde son violentados.

Como generación, estas infancias han estado expuestas a la normalización de la crueldad y el terror a través de la exhibición de la muerte en sus barrios. La burocracia de la muerte violenta en la calle los ha llevado a familiarizarse con los servicios forenses y los diferentes cuerpos policiacos y militares que circundan los lugares donde viven. En comparación con generaciones anteriores, estas niñas y niños han tenido menos oportunidades de jugar en la calle de manera segura, dado el reforzamiento del aislamiento social y la consiguiente pérdida de su autonomía relativa. 


\section{Narrar la violencia crónica: un ejercicio desde la voz y experiencia de niñas y niños}

Existen pocos esfuerzos para documentar de qué hablan niñas y niños que están creciendo en lugares donde la violencia ha perdurado durante años, a pesar de que en estos contextos las narrativas de las experiencias cotidianas son centrales para entender los modelos interpretativos de la niñez sobre las violencias. Esto es particularmente importante cuando se presume que al crecer en entornos dominados por la violencia, niñas y niños aprenden a normalizarla. La "normalización de la violencia" entre infancias que viven en contextos donde priman formas de intimidación, crimen y agresiones cotidianas, supone una mirada crítica con el propósito de no patologizar o criminalizar a las infancias y familias afectadas por estos entornos. Pero, para niñas y niños, la rutina de crecer en un mundo violento no está exenta de reflexiones profundas sobre lo bueno y lo malo, lo aceptable y lo intolerable. Por un lado, el discurso de la normalización encierra el peligro de aceptar, e incluso justificar y legitimar, que la regla y el destino de niñas, niños, sus familias y comunidades, sea la violencia. Por el otro, sugiere un bloqueo de la sensibilidad, falta de conciencia y exceso de tolerancia o indiferencia. Estos elementos acusan la precariedad moral de los sujetos. Por ese motivo, la negociación del sentido de la violencia entre niñas y niños que han crecido con ella cobra relevancia.

En contextos donde la violencia y la impunidad configuran una norma social de hecho, hablar sobre violencia no es tan productivo como hablar sobre aquello que ocurre en el día a día. La vida cotidiana teje tiempos y espacios en los que es posible percibir la violencia que estructura las experiencias de niñas y niños, y que, de acuerdo con Cantoral (2016: 75), "no es insignificante, es cotidiano y por ello puede pasar desapercibido". Con base en esta premisa, el foco de las narrativas aquí estudiadas desplazó a la violencia en sí misma y ponderó el relato de lo cotidiano. En parte, porque las niñas y niños con los que conversé no suelen hablar de violencia, más bien relatan situaciones o eventos concretos, cosas que han visto o les están sucediendo. Se trata de eventos que se muestran comunes y no extraordinarios, aunque no por ello dejan de ser cuestionados o juzgados por sus relatores. Sus narrativas no definen violencias específicas, la mayoría de las veces son relatos inacabados, que aparecen como chismes, comentarios y conversaciones sobre su vida en el barrio, en sus hogares o sobre sus relaciones con amigos y vecinos.

El estudio de las narrativas que producen niñas y niños ha tomado relevancia en las últimas décadas. Desde la antropología y la sociología de la infancia, y los estudios sobre infancias y educación, se han diversificado y promovido los esfuerzos para comprender de qué hablan niñas y niños, y cómo cuentan sus historias. Dar voz a las infancias para capturar sus puntos de vista sobre diferentes temas se ha vuelto un imperativo, y con ese propósito se han creado espacios y metodologías para escucharlos y dialogar con ellos. 
Una de las principales problemáticas en el estudio de las narrativas infantiles es el dilema de representación y autoría que se desprende precisamente de la intención de darles voz. De acuerdo con Nunes y Carvalho (2007), la autenticidad de aquello que definimos como la voz de las infancias depende de los procesos de mediación, interpretación y traducción a cargo de los adultos. Para las autoras, no se trata sólo de "dejarlos hablar" o "expresar sus puntos de vista", darles voz implica reconocer su agencia al contar y la contribución única de sus perspectivas y experiencias a la comprensión de la vida social.

Considerando que las infancias son generalmente representadas por adultos que actuamos como relatores de sus experiencias, Viana, Imbrizi y Jurdi (2017) reconocen que en la reinterpretación de estas narrativas anida el riesgo de que la perspectiva adulta se imponga a la experiencia de niñas y niños. Adicionalmente, se debe considerar el ordenamiento lógico que los adultos ejercen en las narrativas infantiles, restringiendo sus formas propias de narrar. Estos señalamientos exigen una disposición epistemológica para capturar las narrativas de niñas y niños desde un abordaje que no traicione la lógica de sus emisores. Siguiendo a los mismos autores, para recuperar los relatos de las infancias es necesario tomar en cuenta otros modos de comunicación y lenguaje, donde estén presentes la fantasía, la imaginación y la creación como componentes del encuentro y del diálogo. Contrariamente a algunos géneros narrativos presentes en la etnografía, caracterizados por privilegiar las historias como productos acabados, Cardoso (2012) propone estar abierto a las poéticas del contar, es decir, a las maneras en que emergen los relatos, lo que permite entender no sólo el contenido de las historias, sino reconocer sus formas y contextos de enunciación (Briggs, 1996).

Para acceder a las narrativas contadas por niñas y niños, Hartmann (2013) considera que es fundamental reconocerlos como actores sociales autónomos y productores de cultura. Eso implica pensar sus relatos como formas de hacer el mundo, producciones culturales a través de las cuales performativizan su vida e integran en lo que cuentan elementos de ellos mismos y de sus entornos. Para los propósitos de este estudio, se entiende por narrativas aquellos relatos que en su creación permiten abordar las experiencias multidimensionales de los sujetos (Bruner, 1997; Maluf, 1999), es decir, elaboraciones que en el acto de contar implican a la niña o al niño como sujeto social, pero también, como sujeto biográfico. La narrativa es el principio que organiza la experiencia en los propios términos de los actores sociales, articulándose e involucrando la negociación y la renegociación de significados entre el sujeto que cuenta, sus experiencias en el mundo social y su audiencia.

Además de ser un punto de encuentro entre niñas y niños, la escuela es un espacio donde circulan narrativas producidas por ellos mismos, teniendo como principal audiencia a otros pares, y es en ésta donde se puede acceder con mayor facilidad a lo que niñas y niños cuentan entre sí. En el ámbito escolar circulan las historias que acontecen en el barrio, ya sea eventos de los que fueron testigos directos o relatos que reproducen de chismes y comentarios que escu- 
chan en su casa, la calle o en las noticias que se publican en las redes sociales del sector. Otros aspectos más íntimos se comparten entre grupos de amigas y amigos, vinculados con las situaciones que viven con otras niñas y niños en casa, con sus hermanos, padres u otros familiares. Algunos de los silencios del barrio se reproducen también en la escuela. Aquello de lo que no es conveniente hablar afuera, generalmente tampoco conviene contarse adentro.

Más allá de estas tensiones y de las violencias que también se reproducen en el espacio escolar, al compartir, niñas y niños generan formas de acompañamiento, estrategias de contención y consuelo, por lo tanto, como dicen Passeggi, Nascimento y Rodrigues (2018), la escuela es un "refugio y retorno a la vida". No obstante, y como señala Santos (2004), la escuela representa el dominio de lo cognitivo, en donde el saber formal impone el cuestionamiento "¿tú qué sabes", desplazando a la pregunta "¿tú qué sientes?". A pesar del silencio o acallamiento de la vida emocional en los entornos escolares, la dimensión afectiva es la que niñas y niños más recuerdan tras sus experiencias educativas. Desafortunadamente, la urdimbre de afectos y emociones que se tejen en las comunidades escolares se mantiene oculta o se niega, como si no existiera, no por los más pequeños sino, principalmente, por los adultos que participan en la comunidad escolar. Con el fin de no ser blanco de las violencias que operan alrededor de la vida de sus estudiantes, el acallamiento del mundo emocional en estos contextos, que silencia duelos, pérdidas, temores, miedos y abusos, se ha convertido en una forma de protección para el personal docente. Por lo tanto, se pretende que estas situaciones queden "fuera" de la vida escolar.

\section{Metodología}

Retomando la escuela como espacio de encuentro y circulación de narrativas, el objetivo general de este trabajo es reconocer la manera en que la violencia crónica estructura la vida de las infancias y cómo, bajo estos contextos de vida, los grupos de amigos establecen vínculos afectivos y de resiliencia. A medida que profundizamos en sus historias a partir de un enfoque etnográfico y desde las narrativas que producen niñas y niños, es posible identificar diversas formas de violencias que han vivido a lo largo de sus cortas vidas, perpetradas por diferentes actores de su entorno inmediato, ya sea miembros del mismo grupo familiar, vecinos y otros pares. A pesar de que las violencias que los afectan son muy diversas, graves, intensas y reiteradas, niñas y niños difícilmente encuentran apoyo para la contención de sus experiencias y son pocos los tutores adultos, legos o profesionales, dispuestos a escucharlos. Por esta razón, en este artículo desarrollo un aspecto central relacionado con saber, por un lado, cómo describen niñas y niños la vida cotidiana en un barrio donde la muerte violenta y las prácticas de despojo se han sostenido desde hace más de una década, y, por el otro, cómo y con quién compartieron o comparten sus vivencias en momentos de mayor gravedad y sufrimiento.

El dato etnográfico se elaboró a través de ruedas de conversación entre niñas y niños, y observaciones durante clases, a la hora de entrada, de salida y el recreo. Ya que el indagar sobre 
los universos infantiles implica también aproximarse a sus cuidadoras, familiares, profesorado y otras autoridades, se entrevistó adicionalmente a personal directivo y docente, así como otros actores del entorno escolar. De manera informal, también se conversó con algunos familiares de niñas y niños. Finalmente, se hicieron entrevistas con funcionarias y funcionarios de la Defensoría Municipal para la Protección de Niñas, Niños y Adolescentes (NNA) que trabajan en la zona. Integrar a estos actores no significa negar la agencia de niñas y niños, al contrario, es una manera de reconocer que las formas en que proponemos vincularnos con las infancias han sido consensuadas también con esos adultos que están al cargo. Eso nos brindó la posibilidad de otros discursos y aproximaciones a la vida cotidiana del barrio y de las niñas y niños.

La literatura aconseja evitar los momentos a solas con menores y promover encuentros en los que estén acompañados, de preferencia en presencia de otros pares, eligiendo sobre todo espacios abiertos para la interacción, como manera de propiciar mayor confianza, condiciones que se favorecen mediante las entrevistas grupales o en duplas (Mayall, 2000; Martins, 2011). Las ruedas de conversación se propusieron con la finalidad de resguardar de manera sensible a niñas y niños de los efectos de revivir momentos difíciles de la vida, inclusive traumáticos, a través de la investigación social. En primer lugar, se privilegió la metodología grupal y participativa porque facilita la exploración de múltiples aspectos individuales, pero también, de la vida colectiva, produciendo conocimiento a partir de la interacción (Freeman, Mathison, 2009). En segundo lugar, en este trabajo se evitó preguntar directamente a los niños por sus experiencias de sufrimiento derivadas de la violencia (Veale, 2005; Lykes, 2001). Por último, la metodología propuesta buscó conectar con la propia creatividad de los participantes a través del dibujo. Como propone Gobbi (2014), el dibujo es un ritual con la capacidad de crear relaciones y ambientes, y de promover diálogos y análisis comparativos entre los participantes. De ese modo, en las ruedas de conversación entre amigos los participantes crearon un personaje en esencia real, que también era una niña o niño de su edad y vivía en el mismo barrio (Fotografía 1). El personaje tomaba forma con las historias y experiencias que contaron sobre su barrio.

Sin abordar de manera directa las violencias, las conversaciones generalmente se desprendían de preguntas simples sobre los personajes creados: ¿Qué cosas pasan en la calle donde vive? ¿Cómo es su barrio? El punto de partida fue con preguntas como ¿qué sucede en tu barrio, tu escuela, tu familia? ¿qué te ha pasado en los últimos días?

Un aspecto alentador de la metodología fue la capacidad de potenciar la agencia narrativa de niñas y niños, quienes utilizaban el personaje para hablar de sí mismos en tercera persona cuando deseaban contar situaciones vergonzosas o difíciles, pero también, para acentuar el carácter confidencial de ciertas conversaciones. Otro aspecto interesante fue su capacidad de generar un espacio para la imaginación a través del personaje, y con ello, la oportunidad de proyectar otras realidades posibles, agregando rasgos ficcionales al personaje, modificando su historia, sus condiciones actuales, oportunidades, posibilidades y destino. 
Fotografía 1. Elaboración de personaje en esencia real a través de ruedas de conversación

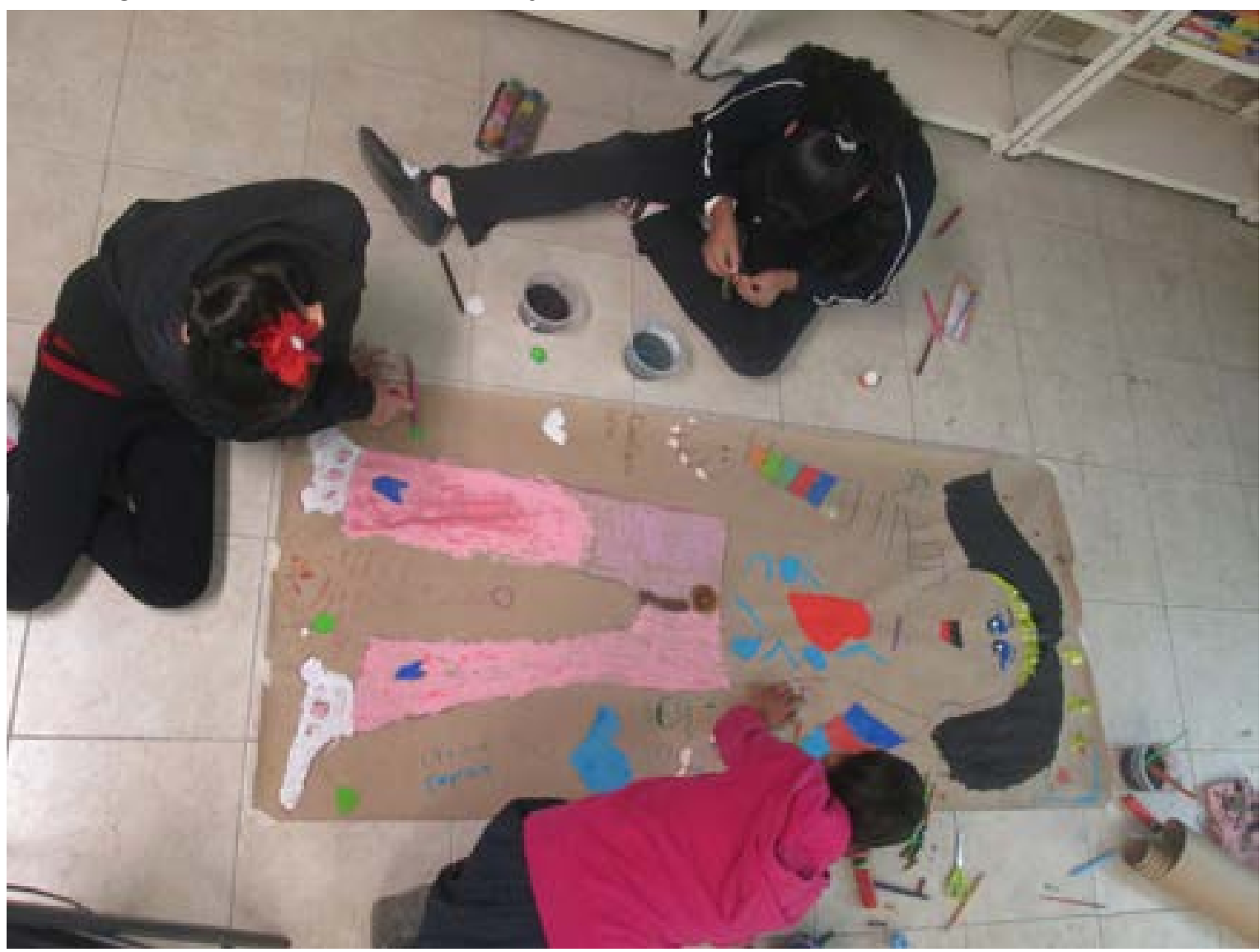

En el ejercicio narrativo de transformar lo vivido en una historia contada, las ruedas de conversación fueron útiles para poner a niñas y niños en contacto con experiencias difíciles y organizarlas, para hacer de estas historias algo más comprensible y susceptible de ser comunicado. En este contexto, los grupos y los juegos narrativos funcionan como estímulo y forma de protección para compartir experiencias dolorosas, pues la experiencia grupal trasmite un sentimiento de confianza entre niñas y niños afectados por situaciones o contextos comunes. Bajo esas condiciones, la contribución individual se ve reforzada por el grupo y, posteriormente, se cubre bajo un cierto anonimato (Freeman, Mathison, 2009).

Eilis Hennessy y Caroline Heary (2005) ofrecen una buena síntesis respecto al uso de metodologías grupales con niñas y niños en la investigación social. Señalan que el trabajo en grupo propicia la relajación de los participantes, ya que no se ven obligados a responder de manera individual a las preguntas del investigador, por lo tanto, amenizan la asimetría de la relación investigador/adulto con su interlocutor. Para estos autores, los grupos ayudan a crear un ambiente seguro entre pares y estimulan la participación. A partir de las respuestas del otro, se sienten 
compelidos a narrar sus propias historias o puntos de vista. Por su semejanza con la dinámica escolar, la técnica resulta familiar para niñas y niños escolarizados.

Los grupos para las ruedas de conversación se conformaron de acuerdo con el criterio de amistad. Vale la pena decir que ningún grupo propuso ruedas de conversación mixtas de niñas con niños. Esto se debe, principalmente, a que las niñas cuidaban no coincidir con los varones para la dinámica, con motivo de sus agresiones frecuentes hacia ellas. En función de esto se garantizó que los grupos estuvieran constituidos sólo por niñas o sólo por niños.

A través de esta estrategia se documentaron las narrativas orales y pictóricas de 82 niñas y niños (39 y 43 respectivamente) que participaron en las ruedas de conversación. ${ }^{2}$ Se trabajó con 45 estudiantes de tercer grado y 37 de cuarto año nacidos entre 2009 y 2012, con edades de entre 8 y 9 años. Algunos de estos casos fueron estudiados a mayor profundidad, en conversaciones más extensas. El caudal de experiencias registradas es inagotable, y la elección de los casos presentados muestra la violencia descarnada en su multiplicidad. En general, se trata de casos que fueron ampliamente discutidos en grupos de amigos.

\section{La violencia crónica en la zona norte de Monterrey: condiciones de vida, instancias gubernamentales y silencios}

Poco después de volver del recreo, sintieron que los muros de los salones se cimbraron cuando una granada detonó en las proximidades de la escuela. Fue imposible contener la curiosidad de las niñas y niños que corrieron para ver lo que sucedía, arremolinándose en los barandales del segundo piso. A lo lejos, escucharon el rechinar de las llantas de la camioneta en la que huía el grupo de jóvenes armados que había atacado a una unidad de Fuerza Civil, cuerpo policiaco de Nuevo León. Era septiembre de 2012. La colonia, enclavada en las faldas del cerro Topo Chico al norte de Monterrey, estaba inmersa en una guerra cotidiana. El evento fue narrado a diferentes voces por el personal docente y de intendencia, y por comerciantes que venden comida, dulces y refrescos alrededor del plantel. Para los habitantes de la colonia era una experiencia habitual de aquellos años difíciles en los que comenzaron a multiplicarse los asesinatos, pero también las desapariciones forzadas de jóvenes de la zona; si bien estos últimos fueron disminuyendo después de 2014, el negocio de las armas de fuego y los homicidios juveniles continúan hasta ahora.

2 Los criterios para seleccionar a las niñas y niños fueron: vivir en el sector estudiado; ser estudiante de tercero o cuarto año en alguna de las dos escuelas primarias del sector y tener entre 7 y 10 años. La propuesta metodológica fue discutida en primer lugar con el equipo de investigación del Ciesas Noreste y el personal de la Defensoría Municipal para la Protección de NNA de la zona, quienes facilitaron el acceso a las escuelas primarias del sector. El permiso de los familiares o tutores para trabajar con los menores fue gestionado por los directivos de las escuelas. Niñas y niños fueron informados sobre el estudio y decidieron participar voluntariamente. Debido a que algunos menores se encontraban en procesos de custodia, y otros eran agredidos por vecinos o miembros de su propio grupo doméstico involucrados en actividades criminales, se dio un tratamiento reservado a los datos mediante confidencialidad cualificada (Groisman y Scheneider, 2014). Para ello se omiten y/o modifican datos primarios o secundarios que faciliten la identificación de los sujetos, tanto menores como adultos. De igual manera, se omite el nombre de las escuelas y barrios estudiados. 
Desde entonces, se ha multiplicado también la población del barrio. Muchas familias jóvenes, indígenas y mestizas, han llegado en búsqueda de mejores oportunidades de vida, huyendo de la violencia social que invadió la mayor parte de las zonas rurales de Veracruz y San Luis Potosí, pero también los municipios periféricos del área metropolitana de Monterrey. El movimiento migratorio es intenso y se refleja en la matrícula de las escuelas. Niñas y niños estudian en promedio de tres a cuatro años en los planteles del sector.

Además de las familias, que se caracterizan por tener una intensa movilidad, existen otros grupos familiares que viven desde hace más de treinta años en el barrio. Están constituidos por los primeros colonos que se asentaron en predios irregulares, que por entonces funcionaban como basureros. Estas familias habitan propiedades grandes donde se concentran varios hogares y coinciden hasta cuatro generaciones.

Desde su conformación, el sector ha estado marcado por la violencia política que condicionaba servicios y recursos por el voto de los líderes en turno. También, por la presencia histórica de pandillas. En la actualidad, además de las batallas y agresiones entre estas últimas, las violencias vividas por niñas y niños que habitan este sector son diversas y severas: robos frecuentes; allanamientos de morada; amenazas contra la vida de sus familiares; feminicidios y homicidios de parientes cercanos y vecinos; acoso sexual contra niñas y mujeres; abuso sexual; trata de blancas y acceso a redes de pedofilia; abandono de padres y madres por el uso o tráfico de drogas o por estar privados de su libertad (encarcelados); desplazamiento forzoso de barrios, municipios y estados; agresiones severas de animales a manos de familiares y vecinos; violencia policial, especialmente durante las aprehensiones de padres y otros familiares; violencia vial, expresada en el miedo a morir atropellados o en un accidente de tráfico, que son comunes en el sector.

Esto sucede en un sector donde la composición poblacional es joven. De acuerdo con datos de la Defensoría para la Protección NNA, en el municipio de Monterrey, 30.4\% de la población son NNA, es decir, un poco más de 345 mil habitantes. La zona norte del municipio concentra casi $28 \%$ de NNA de todo el municipio y destaca por ser uno de los sectores donde se concentra la población infantil, que representa la tercera parte de la población.

Para las familias jóvenes con hijos pequeños, uno de los principales atractivos de este sector es su conectividad con otros puntos de la ciudad a través del transporte público, la oferta de empleo en algunas fábricas cercanas y la existencia de escuelas públicas para educación básica. Una parte importante de las escuelas de todo el municipio convergen en esta área. En las 143 colonias que componen la zona norte se localizan más de 90 planteles de educación básica y media. La proximidad de las escuelas hace posible que la mayoría de niñas y niños caminen para ir y volver del plantel. La cercanía facilita también la participación de las familias en actividades escolares y les permite extender las relaciones de cuidado como, por ejemplo, llevarles los alimentos a la hora del recreo o acompañarlos en su camino a la escuela o de regreso a casa. 
La zona norte de Monterrey está catalogada como uno de los polígonos de intervención prioritaria del municipio. Además de una unidad de la Defensoría Municipal para la atención de casos de maltrato, se concentran ahí diferentes instancias del sistema de protección y otras dependencias para la atención de las infancias y sus familias. Estos centros ofrecen diferentes servicios, entre los que destacan talleres deportivos, artísticos y lúdicos, clubes de tareas y atención psicológica. A pesar de la oferta, el acceso a estos es poco frecuente entre la población infantil estudiada. Las jornadas de trabajo de los tutores se prolongan por muchas horas o, por el contrario, son irregulares, por lo tanto, se complica la planeación de actividades diarias y extraescolares.

En relación con el acceso a la atención en salud mental, la situación es semejante. A pesar de que existen diferentes centros de atención psicológica y para víctimas en esta zona, siguen siendo muy pocas las niñas y niños que llegan a recibir atención terapéutica. Las entrevistas con especialistas y los casos documentados, revelan que niñas y niños acuden sólo a un par de consultas antes de abandonar el proceso. Las posibilidades de las instancias públicas para brindar atención de manera regular son muy limitadas. En promedio, la capacidad de atención es de una cita cada tres meses y esto desanima a las familias para continuar. Aunado a lo anterior, están las dificultades para llevar a los niños a terapias en horarios laborales. Esta situación ha generado un debate en torno al aparente desinterés por parte de la población para buscar apoyo psicológico para las infancias, que se justifica por la supuesta normalización de las violencias entre las comunidades y familias en las que viven. No obstante, la alta demanda de servicios de salud mental para infancias se comprobó en diferentes instancias, como los Centros de Atención a Adicciones (CAPA), los Centros Comunitarios de Salud Mental (CECOSAM), los Centros Comunitarios de Desarrollo Social y unidades del sistema DIF, los cuales se encuentran rebasados. En estos centros, la mayor parte de las consultas son para tratar casos de depresión, violencia intrafamiliar y de género, duelo y abuso sexual, en ese orden de frecuencia. Los casos de menores con adicciones casi no encuentran cabida puesto que los centros especializados se enfocan en adultos.

En el Instituto de Salud Mental de Nuevo León, coordinado por la Secretaría de Educación Pública, se brinda atención psicológica y psiquiátrica a niñas y niños, quienes son derivados por las escuelas públicas del estado. En esta instancia se atiende cada mes a 700 escolares en promedio, que provienen sobre todo del municipio de Monterrey. De acuerdo con uno de los médicos de la institución, más allá del diagnóstico: "los problemas que estos chavitos traen son sobre todo derivados de situaciones muy complejas. Eso aparece ya en la consulta individual, son niños que están pasando por situaciones de secuestro, de asesinatos, de amenazas muy graves, es decir, de violencia letal sufrida por alguno de sus familiares".

Frente a las dificultades de acceso a servicios de salud mental, las escuelas del sector son un eslabón importante del sistema de protección a las infancias, en tanto que identifican y derivan a niñas y niños que requieren atención profesional. Las instituciones educativas no tienen la 
capacidad para garantizar la atención y dar seguimiento a los casos, por lo tanto, su incidencia es limitada, pero importante para identificar situaciones de riesgo. Los casos documentados demuestran que las crisis que manifiestan niñas y niños en el ámbito escolar se entienden como problemas de conducta, rebeldía o ausentismo escolar.

Decir que las autoridades escolares no consideran los contextos sociales que han generado estos comportamientos es inadecuado o al menos reduccionista. De acuerdo con Castellanos (2016), las comunidades que se enfrentan a la violencia desarrollan medidas inéditas para la trasmisión de información que resultan indispensables para mantenerse a salvo. El personal docente promueve el ocultamiento y negación de lo que sucede fuera de la institución. Se pretende que la escuela sea un espacio en donde las situaciones sociales conflictivas y problemáticas del barrio queden fuera. El silencio se convierte en una forma de protección para los adultos $y$, desde su punto de vista, una manera de resguardar también a los estudiantes. Además, para el personal docente, la sobrecarga de trabajo y la conducción de grupos numerosos les impide abrir espacios de escucha activa, aún sean informales con sus alumnos. La política del silencio y la falta de oportunidades para escuchar a los estudiantes contrasta con la necesidad de niñas y niños de hablar acerca de lo que sucede en sus comunidades y en sus vidas.

Los eventos etnográficos que presento a continuación apuntan a la participación de grupos de amigos en el relato de situaciones y eventos desafortunados en la vida de otros pares; al mismo tiempo, demuestran la búsqueda permanente para hablar y ser escuchados, y por encontrar mecanismos de ajuste y reparación ante el dolor de pérdidas, amenazas y abusos.

\section{Los relatos de la bolita: narrativas, amistad y violencia}

Con curiosidad, Deisy asomó la cabeza por el salón y cuando vio los materiales de pintura sobre el piso, se emocionó y dijo "qué bueno que sí vine, profesora, es que ya casi no iba a venir [a clases] porque ayer en la noche iban a matar a mi primo". Las niñas, que eran parte de su grupo de amigas, pararon lo que estaban haciendo para preguntar lo que había sucedido y se sentaron para escucharla con atención. Deisy contó que a medianoche llegó un hombre hasta la puerta de su casa buscando a su primo para saldar una deuda de dinero. El hombre traía un machete y su primo resultó gravemente herido. Fue la madre de Deisy quien se hizo cargo del muchacho, llevándolo de urgencia en un taxi hasta el hospital, pues la madre del joven estaba trabajando en un supermercado que brinda atención las 24 horas. Una de las niñas comentó: "ya merito no vienes a clases como cuando tu abuelita, ¿no?". Entonces Deisy me explicó que hacía unos meses tuvo que faltar a clases tras la muerte de su abuela. Cuando le pregunté de qué había muerto, sus compañeras respondieron al unísono: "de tristeza". La respuesta me inquietó y Deisy me platicó lo sucedido. El hijo mayor de su abuela es un hombre violento que en diferentes ocasiones ha agredido a las mujeres de su familia. En uno de los episodios atacó a su pareja que estaba embarazada y le provocó un aborto. Su abuela era una mujer joven y diabética que 
se desempeñaba como trabajadora doméstica "ella ya estaba mal, y ya no se sentía bien, y una tristeza te mata cuando estás mal del azúcar y por eso se murió". De manera alterna a la narración de Deisy, aparecen las voces de sus amigas para comentar otros detalles: "es que el tío es muy malo, les pega, les roba dinero y ya ni saben qué hacer con él”, "no era la primera vez que le pegaba a la muchacha, ¿verdad?", "le pegó en el bautizo de su primo", "su abuela dejó de comer y ya no se compuso". Deisy asentía con la cabeza, dejando al grupo de niñas contar la historia como si fuera propia. Las amigas refirieron que Deisy estuvo afligida durante semanas y entre ellas encontraron modos para reanimarla: "una vez que Deisy estaba llorando, nos metíamos al baño y atorábamos la puerta con una escoba [risas], es que, si no, los chamacos se burlan", "te llevábamos chicharrines, ¿no, tú?", "ese día la mojamos con el bebedero, y se enojó porque estaba triste".

Fotografía 2. Dibujo y relato de Deisy: "Es el corazón de mi abuela, se rompió porque mi tío mató a su nieto. La de atrás es mi abuela que ya se murió"

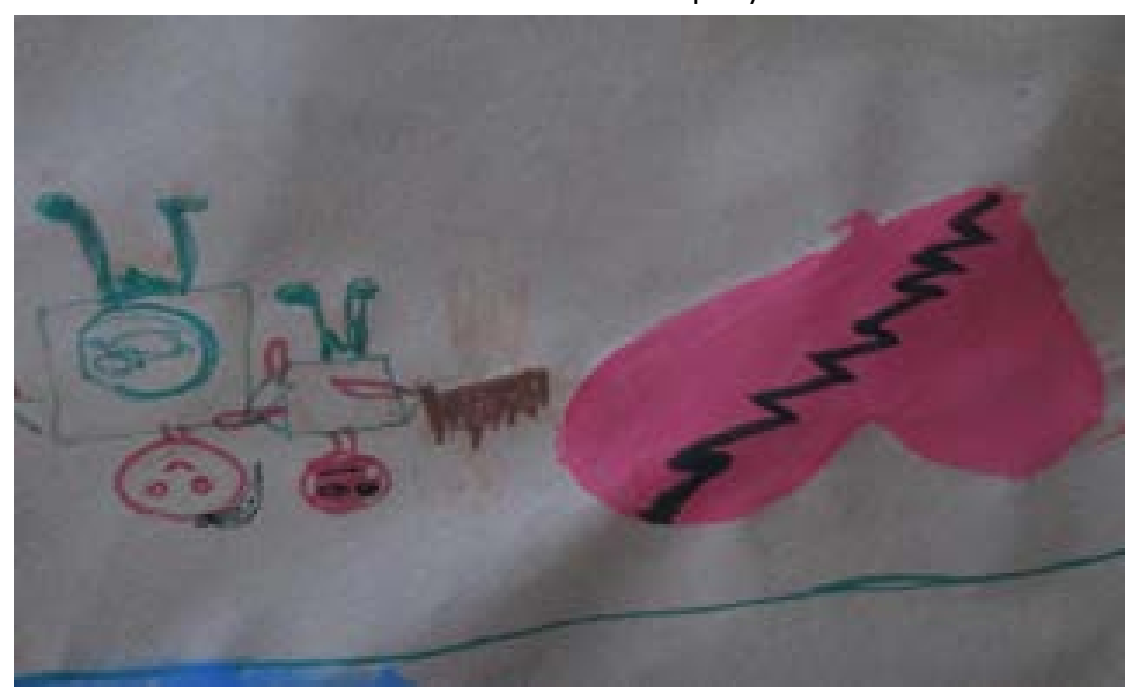

La participación de amigas y amigos en los relatos de sus pares no era aislada. Al contrario, se veía fortalecida por la estrategia metodológica de organizar los grupos bajo el criterio de afinidad y amistad, o en los términos de los propios niños de la bolita, es decir, del grupo de amigos quienes intervenían para brindar detalles o llamar mi atención sobre datos o aspectos que no habían sido mencionados. Solicitaban más información, hacían preguntas o reflexiones al respecto de acontecimientos actuales o pasados. Vinculaban eventos para producir teorías, hipótesis o resaltar la gravedad de las situaciones vividas. Con ello, demostraban lo mucho que estaban al tanto sobre las situaciones que atravesaban sus compañeros de clase.

Otro evento semejante se dio entre el grupo de amigas de Keny (7 años), que habían sido víctimas de tocamientos sexuales por parte de familiares y vecinos. Un par de ellas eran vecinas 
y fueron agredidas en la misma fiesta de cumpleaños. El hombre, quien también les propuso tomar fotografías de sus cuerpos, era el abuelo de una amiga en común. Los casos de pornografía infantil no eran aislados. Al menos siete participantes relataron situaciones en donde personas adultas les habían propuesto a ellos o a otros pares hacerles fotografías sexuales.

En septiembre de 2018 , la captura de un hombre en posesión de teléfonos celulares y números de menores de edad cimbró a la comunidad. La mayor parte de las niñas y niños del sector conocían los hechos, porque el hombre fue perseguido por una turba que buscaba lincharlo al descubrir que había estado fotografiando a una niña. Este antecedente cobró relevancia cuando conocí el caso de Keny y su hermana.

Después de una jornada trabajando con el grupo de Keny y sus amigas, las niñas que habían narrado las agresiones sexuales me pidieron que nos reuniéramos una vez más porque Keny tenía algo para contar. Las niñas llegaron con un aire solemne al salón, cerraron las puertas y ventanas para asegurarse de que nadie más escucharía, y dijeron: "ahora sí, Keny, cuéntale lo que te pasó". La hermana de Keny, Bety de 12 años, fue víctima de trata de blancas por parte de un joven de 17 años, quien comenzó a cortejarla en 2018 en su mismo barrio. En algún momento, este joven le regaló a Bety un teléfono celular mediante el cual la niña le enviaba fotografías de ella desnuda. Más adelante, el joven la convenció de huir con él. La niña fue drogada, violada y prostituida, quedó embarazada y logró abortar. El joven finalmente fue preso, y la niña volvió al hogar con sus padres. Desde entonces, Keny tomó el lugar de mediadora entre su hermana y el resto de la familia:

Yo le dije:"Bety, tú hiciste algo malo porque no te tenías que ir con él si tú no querías. Él no te tenía que forzar", y ella dijo:"pero yo lo quiero Keny, porque fue el primer amor que tuve". Y yo le dije:"Bety, pero tú tenías 12 años y él tenía 17, más aparte te drogó y te hizo cosas muy feas, tuviste moretones"."Y todavía lo amo", así decía.

Luego, cuando fue al psicólogo, ella golpeaba a la señora, no quería ir y luego le tenían que poner un tranquilizante y se calmaba. Pero la señora le repetía cómo fue todo lo que vivió, y eso a ella la lastimaba. A ella no le servía nada porque volvía a lo mismo, recordaba las cosas y no le gustaba recordar porque sentía que toda su vida se derrumbó. Nosotros tuvimos que quebrar su celular porque ya no lo queríamos. Bety golpeaba a mi mamá, no la quería nada y menos a mi papá, porque mi papá lo metió a la cárcel a él.

Cuando vimos el celular del muchacho, porque lo hallamos, ahí tenía puros contactos de hombres y salían fotos de ella desnuda, vendiendo su cuerpo. Y a mi mamá, cuando la dejaron sola —nosotros fuimos a llevar a mi hermana al psicólogo - mi mamá se quiso suicidar. Ya no aguantaba con ella. Mi mamá sintió muy feo cuando vio esas fotos que vendían su cuerpo de su hija. Mi mamá vio el celular y vio que todas las muchachas cuando vendían su cuerpo ya estaban todas muertas [sic.]. Yo llegué de volada y mi mamá estaba con un cuchillo y yo me asusté mucho y mi hermana no hizo nada, nomás se 
quedó así. Mi papá le agarró el cuchillo a mi mamá, se lo tiró, y mi mamá se quedó así. Y mi papá agarró el celular y estaba viendo las fotos y él sentía súper feo y le dijo "Bety, ¿qué es esto?", "soy yo apá, vendiendo mi cuerpo" y nos dijo "pero era para irnos a la casa". Y mi hermano se enojó mucho con ella y ya no la querían ver.

Todo ha sido muy feo. Lo más feo fue, porque un día teníamos un perrito y ella lo mató, tenía coraje y lo mató al perro y ella tenía coraje porque no la dejaban ver al muchacho, y ese perro era de ella y mío y lo mató y le dije "Bety, ¿por qué hiciste eso?" [llora] y sentí súper feo porque no la podía controlar y me sentí horrible y le dije “iBety, ya aplácate, me estás asustando!" y me empezó a corretear. Y yo me fui y la encerré, y cuando llegaron había muchos señores ahí porque vieron que ella me cortó aquí y vieron que tenía la cortada, y mi mamá me llevó y se enojó mucho con mi hermana, y me abrazó y me llevó al hospital y me tuvieron que coser. Y mi hermano se sintió mal por mí, me abrazó y lloró mucho conmigo y fue muy triste porque ese día iba a ser un día feliz porque mi hermano me iba dar la noticia de que va a ser papá.

Keny asistió a una sesión de terapia con la misma psicóloga que atendió a su hermana. Los esfuerzos familiares e institucionales se centraron en la víctima directa, sin extender la atención a las otras personas de la familia. Por lo tanto, para Keny, sus amigas eran un soporte importante y cotidiano en este proceso. Con ellas hablaba de los esfuerzos para que sus padres y hermano volvieran a hablar con Bety y aceptarla; de las tensiones de vivir en un hogar donde su madre intentó quitarse la vida y su hermana estaba profundamente traumatizada. Sus amigas intervenían diciendo: "es que Keny siente que fue su culpa lo que le pasó a su hermana y no fue su culpa, a su hermana la abusó ese muchacho"; "sus papás siempre están muy enojados y ya no tiene tranquilidad en su casa"; "la doctora le dijo que es buena hija y que se concentre en la escuela"; "ya no se puede hacer nada, todo eso ya pasó"; "un día, va a pasar mucho tiempo y ya todo lo de tu hermana se les va a olvidar, ¿verdad?".

Así como los casos reseñados, otros muchos se animaban a contar sus historias diciendo "cuéntale lo que le pasó cuándo...." Se estimulaban a platicar casos o detalles, los reconfortan y los alientan a no sentir miedo o vergüenza, o también, les ayudan a entender su situación. Por ejemplo, cuando Víctor se mostró apenado por asumir que su madre era usuaria de drogas y prostituta, su mejor amigo lo reconfortó diciendo: "que no te de pena, ya sabes que mi mamá hace lo mismo".

\section{Conclusión}

Desde la antropología de las infancias se ha señalado la necesidad de recuperar los modelos explicativos de niñas y niños. La realidad presentada no sólo abona a la comprensión de las relaciones horizontales entre niñas y niños, produciendo y habitando espacios donde estar juntos promueve una búsqueda por comprender el espacio donde viven como menores de edad y su- 
jetos vulnerables, sin que esto los defina. Las investigaciones sobre las narrativas que producen los más pequeños nos colocan ante un gran desafío: la necesidad de incluir en sus relatos sus propias voces, pero también la participación de otros actores en el proceso de escuchar, contar y trasmitir sus experiencias, en este caso, la intervención de otras niñas y niños.

Como podemos observar en los casos estudiados, la abundancia de experiencias dolorosas en contextos de violencia crónica es inagotable, pero las infancias no sucumben a la indiferencia, por el contrario, son capaces de demostrar empatía frente al dolor de sus compañeras y compañeros, y de buscar de manera activa formas para consolarlos. La participación de las infancias en estos procesos ha sido invisibilizada, pese al importante lugar que ocupan como compañeros en la adversidad, principalmente, en contextos en donde el acceso a servicios de salud mental es tan restringido.

De igual forma, en sus grupos domésticos son pocos los que han logrado hablar sobre las situaciones que enfrentan con adultos que los acompañen y puedan ayudarles a transitar por estas experiencias y a tratar de procesarlas. En general, los mecanismos de contención en sus hogares son limitados, pues los mismos adultos están envueltos en dinámicas igualmente perniciosas.

Finalmente, a pesar de que en la escuela la trama de emociones y afectos que se derivan de la violencia crónica se mantiene oculta, es innegable que el espacio escolar representa un espacio para el encuentro y desarrollo de relaciones afectivas que puede favorecer el proceso de reparación, a través de un acto aparentemente baladí: los mecanismos de ajuste que se generan cuando niñas y niños comparten entre ellos mismos sus experiencias.

Las infancias que se viven en estos contextos ya no pueden ser vistas como un conjunto afectado tangencialmente o como testigos pasivos que sólo escuchan y ven lo que pasa alrededor. Niñas y niños son actores sociales que encarnan las violencias, elaboran teorías para explicarse lo que les sucede, movilizan estrategias de contención, desahogo y acompañamiento que no involucran a los adultos, y formas de resistencia como la amistad y la escucha, que no están exentas de tensiones, pero les permiten abrirse paso en el día a día.

Es urgente dar atención y acompañamiento psicosocial a niñas y niños víctimas de violencia. El debate público sobre la infancia en México y la violencia que se vive en el país, implica pensar a las infancias como agentes activos ante los fenómenos que los afectan y sobre la necesidad de políticas públicas que puedan no sólo evitar su sufrimiento sino contenerlo.

\section{Referencias}

Adams, T. (2014). Chronic Violence and Non-Conventional Armed Actors: A Systemic Approach. NOREF Report. https://www.clingendael.org/publication/chronic-violence-and-non-conventional-armed-actors 
Briggs, C. (1996). Introduction. En Briggs, C. (ed.). Disorderly Discourse, Narrative, Conflict and Inequality. Oxford: Oxford University Press.

Bruner, J. (1997). Atos de significação. Porto Alegre: Artes Médicas.

Cantoral, G. (2016). Vida cotidiana: uso/ocupación del tiempo/espacio y reconfiguración identitaria de género en San Cristóbal de Las Casas, Chiapas. LiminaR, 14(2), 70-84. http://www. scielo.org.mx/scielo.php?script=sci arttext\&pid=S1665-80272016000200070\&lng=es\&tln $\mathrm{g}=\mathrm{es}$

Cardoso, V. (2012). Marias: a individuação biográfica e o poder das estórias. En Gonçalves, M. A; R. Marques; V. Z. Cardoso (eds.). Etnobiografia: Subjetivação e etnografia. Brasil: 7 Letras, 43-62. https://edisciplinas.usp.br/pluginfile.php/5644184/mod resource/content/1/M A Gonçalves Etnobiografia subjetivacao e etnografia.pdf

Castellanos, N. (2016). Antropología de los silencios en la inminencia del conflicto armado. $R e$ vista de Sociología y Antropología: Virajes, 18(1), 13-25. https://revistasojs.ucaldas.edu.co/ index.php/virajes/article/view/3550

Charlot, B. (2002). A violência nas escolas: como os sociólogos franceses abordam essa questão. Interface, 4(8), 432-443. https://www.scielo.br/pdf/soc/n8/n8a16.pdf

Debert, G. (1998). Pressupostos da reflexão antropológica sobre a velhice. En Debert, G. (ed.). Antropologia e velhice. Campinas: IFCH/UNICAMP, 7-27. http://www.mirelaberger.com.br/ mirela/download/td13-guita.pdf

Encuesta Nacional de la Dinámica Demográfica (ENADID) (2018). Principales resultados. México: INEGI. $\quad$ https://www.inegi.org.mx/contenidos/programas/enadid/2018/doc/resultados enadid18.pdf

Encuesta Nacional de Salud y Nutrición (ENSANUT). (2020). Encuesta Nacional de Salud y Nutrición 2018-19. Resultados nacionales. México: ENSANUT. https://ensanut.insp.mx/encuestas/ensanut2018/doctos/informes/ensanut 2018 informe final.pdf

Encuesta Nacional sobre Discriminación (ENADIS) (2017). Principales Resultados. México: INEGI. https://www.inegi.org.mx/contenidos/programas/enadis/2017/doc/enadis2017 resultados.pdf

Freeman, M.; S. Mathison (2009). Defining Researcher Roles in Research with Children. En Researching Children's Experiences. Nueva York: Guilford Press, 53-67. https://www.academia. edu/8727694/Researching Childrens Experience

Gobbi, M. A. (2014) Mundos na ponta do lápis: desenhos de crianças pequenas ou de como estranhar o familiar quando o assunto é criação infantil. Linhas Críticas, 20(41), 147-165.

Groisman, A.; J. Scheneider (2014). Pesquisa qualitativa, saúde e uso de drogas: desdobramentos e implicações teóricas, analíticas e epistemológicas da utilização da técnica da entrevista de fala aberta. Revista Portuguesa de Saúde Pública, (32), 37-44. https://www.sciencedirect. com/science/article/pii/S0870902513000771 
Hartmann, L. (2013). Medo e encantamento em narrativas orais contadas por crianças. Cerrados. Revista de pós-graduação em Literatura, 22(35), 50-67.

Hennessy, E.; C. Heary (2005). Exploring Children's Views through Focus Groups. En Greene, S.; D. Hogan (eds.). Researching Children's Experiences. London: Sage, 236-252.

Instituto Nacional Electoral (2019). Resultados Consulta Infantily Juvenil 2018. México: INE. https:// www.ine.mx/wpcontent/uploads/2019/04/Resultados Consulta Infantil y Juvenil-2018. pdf

Instituto Nacional para la Evaluación de la Educación (2018). Informe Anual 2018: Educación obligatoria en México. México: INEE. https://www.inee.edu.mx/wp-content/uploads/2018/12/ P11243.pdf

Instituto Nacional de Estadística y Geografía (2020). Comunicado de prensa Núm. 024/20. México: INEGI. https://www.inegi.org.mx/contenidos/saladeprensa/boletines/2020/EstSociodemo/DefunHomicidio.pdf

Lykes, B. (2001). Creative Arts and Fhotography in Participatory Action Research in Guatemala. The SAGE Handbook of Action Research. Thousand Oaks: Sage, 363-371.

Maluf, S. (1999). Antropologia, narrativas e a busca de sentido. Horizontes Antropológicos, 5(12), 6982. https://www.scielo.br/scielo.php?script=sci arttext\&pid=S0104-71831999000300069

Martins, R. C. (2011). Pesquisas com crianças: Instrumentos teóricos metodológicos na escuta dos pequenos. $X$ Congresso Nacional de Educação - Educere. I Seminário Internacional de Representações Sociais. Subjetividades e educação - Sirsse. https://educere.bruc.com.br/ CD2011/pdf/5321 2862.pdf

Mayall, B. (2000). Conversations with Children: Working with Generational Issues. En Christensen, P.; A. James (eds.). Research with Children: Perspectives and Practices. United Kingdom: Falmer Press, 120-135.

Nunes, A; R. Carvalho (2007). Questões metodológicas e epistemológicas suscitadas pelas Antropologia da Infância. BIB/ANPOCS, (68), 77-97. https://www.anpocs.com/index.php/papers-31-encontro/st-7/st14-5/2893-carvalho-nunes-questoes/file

Oficina de las Naciones Unidas contra la Droga y el Delito (2018). Mapa georreferenciado de la violencia contra las mujeres en el estado de Nuevo León (2008-2017). México: ONODC. https:// www.nl.gob.mx/sites/default/files/mapas georrefenciado iemujeres - onud.pdf

Passeggi, M.; G. Nascimento; S. Rodrigues (2018). Narrativas de crianças sobre a escola: desafios das análises. Revista Lusófona de Educação, (40), 155-169. https://revistas.ulusofona.pt/index.php/rleducacao/article/view/6440

Pearce, J. (2019). Introducción. Un aporte conceptual y empírico para resignificar la seguridad en México. En Kloppe-Santamaría, G.; A. Abello Colak. Seguridad humana y violencia crónica en México: nuevas lecturas y propuestas desde abajo. México: Miguel Ángel Porrúa, 5-33. https:// www.casede.org/index.php/biblioteca-casede-2-0/seguridad/seguridad-humana/472-seguridad-humana-y-violencia-cronica-en-mexico 
Reyes, G.; P. Hernández; C. Moslares (2015). Gastos en seguridad y homicidios: los costos de la guerra contra el crimen organizado (2006-2012). Revista Mexicana de Opinión Pública, (18), 93-111. https://www.sciencedirect.com/science/article/pii/S1870730015713621

Robledo, C. (2019). Peinar la historia a contrapelo: reflexiones en torno a la búsqueda y exhumación de fosas comunes en México. Encartes, 2(3), 13-42. https://doi.org/10.29340/en.v2n3.62

Santos, M.A. (2004). Arqueología de los sentimientos en la Organización Escolar. Tendencias Pedagógicas, (9), 45-70. https://revistas.uam.es/tendenciaspedagogicas/article/view/1840

Tassinari, A.; J. Almeida; N. Rebolledo (2014). Introdução. En Tassinari, A.; J. Almeida; N. Rebolledo (eds.). Diversidade, educação e infância. Reflexões antropológicas. Florianópolis: EdUFSC, 7-15.

Veale, A. (2005). Creative Methodologies in Participatory Research with Children. En Greene, S.; D. Hogan (eds.). Researching Children's Experiences: Approaches and Methods. Thousand Oaks: Sage, 253-273.

Viana, C.; J. Imbrizi; A. Jurdi (2017) Narrativas sobre o brincar: aproximação da experiência infantil. Psicologia e Sociedade, (29), 1-12. https://www.scielo.br/pdf/psoc/v29/1807-0310-psoc29-e160002.pdf 